\title{
Optimasi Penjadwalan Mata Kuliah Menggunakan Algoritma Late Acceptence Hill Climbing Berbasis Hiper Heuristik
}

\author{
I Gusti Agung Premanananda*1, Ahmad Muklason ${ }^{2}$ \\ ${ }^{1,2}$ Jurusan Sistem Informasi Institut Teknologi Sepuluh Nopember \\ e-mail: *igustiagungpremananda@gmail.com
}

\begin{abstract}
Abstrak
Penjadwalan mata kuliah merupakan salah satu bidang dari riset operasi. Permasalahan ini menjadwalkan sebuah kelas dengan tidak melanggar satu batasan yang ada. Pada saat ini permasalahan penjadwalan mata kuliah menjadi semakin kompleks dengan banyaknya batasan yang ada. Salah satunya terdapat pada kompetisi International Timetabling Competition 2019 (ITC 2019) yang menggeluarkan dataset real world terbaru.

Penelitian ini berfokus terhadap optimasi kualitas penjadwalan mata kuliah untuk menurunkan nilai penalti pada solusi akhir dari penjadwalan mata kuliah. Algoritma yang digunakan adalah Late Acceptence Hill Climbing(LAHC) dengan pendekatan hiper-heuristik dengan menggunakan Low Level Heuristik(LLH) mutasi dan local search. Algoritma diterapkan terhadap 30 dataset ITC 2019 dengan 100.000 iterasi dalam 5 kali percobaan.

Hasilnya penerapan algoritma ini mampu mengoptimasi dengan rata-rata $52 \%$ dari solusi awal. Selain itu algoritma ini menghasilkann solusi yang konsisten selama 10 kali percobaan di setiap datasetnya.
\end{abstract}

Kata kunci-Penjadwalan Mata Kuliah, Algoritma LAHC, Hiper Heuristik

\begin{abstract}
Course scheduling is one area of operations research. This problem schedules a class without violating an existing constraint. At this time the problem of scheduling courses is becoming increasingly complex with existing limitations One of them is in International Timetabling Competition 2019 (ITC 2019) which released the latest real world dataset.

This study focuses on optimizing the quality of course scheduling in order to reduce the value of the final solution of course scheduling. The algorithm used is Late Acceptance Hill Climbing (LAHC) with a hyper-heuristic approach using mutation Low Level Heuristics (LLH) and local search. The algorithm was applied to 30 ITC 2019 data sets with 100,000 iterations in 5 trials.

The result is that the application of this algorithm is able to optimize with an average of $52 \%$ of the initial solution. In addition, this algorithm produces a consistent solution for 10 attempts on each dataset.
\end{abstract}

Keywords - Course Scheduling, LAHC Algorithm, Hyper Heuristics 


\section{PENDAHULUAN}

Permasalahan penjadwalan matakuliah merupakan permasalahan untuk menjadwalkan mata kuliah terhadap jadwal dan ruangan yang tersedia dengan memastikan tidak ada pelanggaran terhadap hard constraint dan meminimalkan soft constraint [1]. Permasalahan penjadwalan mata kuliah termasuk ke dalam permasalahan NP-Hard karena tidak memungkinkan menyelesaikan permasalahan ini dengan algoritma exact dalam waktu yang wajar. Sehingga penelitian terkini lebih berfokus mengembangkan algoritma dengan pendekatan heuristik [2].

Beberapa penelitian dalam lima tahun terakhir melakukan pengembangan algoritma baru dengan mengembangkan berbagai macam jenis algoritma. Studi yang dilakukan Saviniec [3] menghasilkan algoritma baru dengan menggabungkan Iterated Local search dan Variable Neighborhood Search. Studi lain dilakukan oleh Alzaqebah [4] mencoba menggabungkan algoritma bee colony optimization dengan beberapa algoritma local search. Ada juga studi lain yang dilakukan oleh Skoullis [1] dengan mencoba algoritma hybrid cat swarm optimization pada permasalahan penjadwalan. Dari beberapa penelitian tersebut, penyelesaian masalah penjadwalan mata kuliah masih berfokus terhadap dataset lama, sehingga hasil penelitian tersebut kurang relevan jika diterapkan pada studi kasus saat ini.

Salah satu organisasi mengeluarkan dataset real world terbaru mengenai penjadwalan mata kuliah dari berbagai universitas di dunia lewat sebuah kompetisi bernama International Timetabling Competition 2019 (2019) [5]. Dataset pada ITC 2019 merupakan dataset terbaru dengan tingkat kompleksitas yang sangat tinggi. Dataset ini terdiri dari 30 dataset yang terbagi menjadi tiga kelompok dimana setiap bagian berisi 10 dataset. Tiga kelompok tersebut terdiri dari dataset early, middle dan late. Secara keseluruhan dataset ini memiliki 19 batasan distribusi seperti pada gambar 1 dimana batasan ini dapat berupa hard constraint atau berupa soft constraint. Selain batasan distribusi terdapat juga hirarki dalam setiap mata kuliah seperti pada gambar 2. Tujuan utama dari kompetisi ini adalah menjadwalkan mahasiswa ke dalam matakuliah yang diinginkan dan menjadwalkan kelas pada daftar waktu dan ruangan yang tersedia tanpa melanggar hard constraint yang ada. Nilai penalti menjadi penentu untuk menentukan kualitas dari solusi yang dihasilkan. Solusi dengan penalti terkecil merupakan solusi yang paling baik.

Dalam pengembangan algoritma dengan pendekatan heursitik, terdapat beberapa jenis metode yaitu heuristik, metaheuristic dan hiper heuristik. Metode heuristik mudah untuk digunkan namun sering menghasilkan hasil yang buruk pada beberapa kasus. Metode metaheuristik dapat menghasilkan solusi yang sangat baik, namun metode ini tidak dapat digunakan pada dunia komersial dan industri karena metode ini membutuhkan biaya yang mahal dan susah untuk diterapkan. Sedangkan metode hiper heutistik dapat digunakan dengan cukup mudah, terjangkau , dan lebih mampu menghasilkan solusi yang baik [6].

Berdasarkan latar belakang tersebut maka penelitian ini mengembangkan algoritma LAHC dengan pendekatan hiper heuristik untuk menyelesaikan permasalahan penjadwalan terbaru dari dataset ITC 2019. Penelitian ini hanya berfokus bagian optimasi penjadwalan terhadap 10 dataset pada bagain dataset early. Karakteristik dari 10 dataset yang digunakan dapat dilihat pada tabel 1. Dari penelitian ini diharapkan mampu digunakan sebagai acuan dalam menyelesaikan permasalahan penjadwalan di universitas. 


\begin{tabular}{|llccccc|}
\hline Constraint & Opposite & Time & Days & Weeks & Room & Pairs \\
\hline SameStart & & $\sqrt{ }$ & - & - & - & $\sqrt{ }$ \\
SameTime & DifferentTime & $\sqrt{ }$ & - & - & - & $\sqrt{ }$ \\
SameDays & DifferentDays & - & $\sqrt{ }$ & - & - & $\sqrt{ }$ \\
SameWeeks & DifferentWeeks & - & - & $\sqrt{ }$ & - & $\sqrt{ }$ \\
SameRoom & DifferentRoom & - & - & - & $\sqrt{ }$ & $\sqrt{ }$ \\
\hline Overlap & NotOverlap & $\sqrt{ }$ & $\sqrt{ }$ & $\sqrt{ }$ & - & $\sqrt{ }$ \\
SameAttendees & & $\sqrt{ }$ & $\sqrt{ }$ & $\sqrt{ }$ & $\sqrt{ }$ & $\sqrt{ }$ \\
Precedence & & $\sqrt{ }$ & $\sqrt{ }$ & $\sqrt{ }$ & - & $\sqrt{ }$ \\
WorkDay(S) & & $\sqrt{ }$ & $\sqrt{ }$ & $\sqrt{ }$ & - & $\sqrt{ }$ \\
MinGap(G) & & $\sqrt{ }$ & $\sqrt{ }$ & $\sqrt{ }$ & - & $\sqrt{ }$ \\
\hline MaxDays(D) & & - & $\sqrt{ }$ & - & - & days over D \\
MaxDayLoad(S) & & $\sqrt{ }$ & $\sqrt{ }$ & $\sqrt{ }$ & - & slots over S \\
MaxBreaks(R,S) & & $\sqrt{ }$ & $\sqrt{ }$ & $\sqrt{ }$ & - & breaks over R \\
MaxBlock(M,S) & & $\sqrt{ }$ & $\sqrt{ }$ & $\sqrt{ }$ & - & blocks over M \\
\hline
\end{tabular}

Gambar 1. Batasan Distribusi ITC 2019

\begin{tabular}{|c|c|c|c|c|c|c|c|c|c|}
\hline Course & \multicolumn{9}{|c|}{ Introduction to Mech. Eng. ME 263} \\
\hline Configuration & \multicolumn{4}{|c|}{ Lec-Rec } & \multicolumn{5}{|c|}{ Lec-Rec-Lab } \\
\hline Subpart & \multicolumn{2}{|c|}{ 1_Lecture } & & & \multicolumn{2}{|c|}{ 3.Lecture } & & & \\
\hline Parent & \multicolumn{2}{|c|}{ 2_Recitation } & & & \multicolumn{4}{|c|}{ 4_Recitation } & \\
\hline Child & & & & & & & \multicolumn{2}{|c|}{ 5.Laboratory } & \\
\hline Class & Lec1 & Lec2 & & & Lec3 & & & & \\
\hline Parent & Rec1 & Rec2 & Rec3 & Rec4 & & Rec5 & & Rec6 & \\
\hline \multirow[t]{4}{*}{ Child } & & & & & & & Lab1 & & Lab2 \\
\hline & & & & & Lec4 & & & & \\
\hline & & & & & & Rec7 & & Rec8 & \\
\hline & & & & & & & Lab3 & & Lab4 \\
\hline
\end{tabular}

Gambar 2. Hierarki Mata Kuliah

Tabel 1. Karakteristik Dataset Early

\begin{tabular}{|c|c|c|c|c|}
\hline Dataset & Kelas & Ruangan & Murid & Batasan Distribusi \\
\hline agh-fis-spr17 & 1239 & 80 & 1641 & 1220 \\
\hline agh-ggis-spr17 & 1859 & 44 & 2116 & 2690 \\
\hline bet-fal17 & 983 & 62 & 3018 & 1251 \\
\hline iku-fal17 & 2641 & 214 & 0 & 2902 \\
\hline mary-spr17 & 882 & 90 & 3666 & 3947 \\
\hline muni-fi-spr16 & 575 & 35 & 1543 & 740 \\
\hline muni-fsps-spr17 & 561 & 44 & 865 & 400 \\
\hline muni-pdf-spr16c & 2526 & 70 & 2938 & 2026 \\
\hline pu-llr-spr17 & 1001 & 75 & 27018 & 634 \\
\hline tg-fal17 & 711 & 15 & 0 & 501 \\
\hline
\end{tabular}

\section{METODE PENELITIAN}

Penelitian ini akan melalui beberapa tahapan mulai dari praproses, desain algoritma, implementasi dan analisis hasil. 


\subsection{Pra Proses Data}

Pada dataset ITC 2019, terdapat beberapa kandidat jadwal yang tidak mungkin dapat digunakan selama penjadwalan kelas karena pasti akan melanggar hard constraint yang ada. Sehingga kandidat jadwal tersebut harus dihapus agar tidak mengganggu dalam proses optimasi jadwal. Penghapusan kandidat jadwal dilakuakan berdasarkan konflik dengan ruangan, batasan distribusi dan jadwal kelas lainnya [7].

\section{2 Desain Algoritma}

Pada desain algoritma terbagi menjadi dua bagian yaitu desain LLH yang digunakan untuk mengubah solusi dan yang kedua desain dari algoritma yang digunakan untuk pemilihan penerimaan solusi. Pada desain algoritma ini akan menggunakan dua LLH yaitu mutasi dan local search. Sedangkan algoritma yang digunakan adalah algoritma LAHC.

\section{2.1 LLH Mutasi}

Mutasi akan digunakan saat menjalankan algoritma LAHC dengan tujuan untuk meminimalkan terjadinya pelanggaran hard constraint dengan hanya mengubah jadwal kelas pada list jadwal yang memungkinkan. Mutasi dilakukan dengan cara mengubah beberapa jadwal kelas terhadap jadwal yang tersedia. Seperti pada gambar 3, jadwal pada kelas ke-1 diubah dari yang awalnya dijadwalkan pada slot 10 diubah ke slot 13. Pada kelas ke-3 dari, yang awalnya dijadwalkan pada slot 23 diubah ke slot 27 dan pada kelas ke-3.

Untuk memastikan tidak ada pelanggaran setelah terjadi operasi mutasi, perubahan baru akan terjadi jika tidak terjadi konflik dengan kelas yang lain. Dengan demikian, sebelum melakukan perubahan, akan dilakukan tahapan pengecekan hard constraint dan pengecekan slot jadwal terhadap jadwal baru yang akan digunakan.

Sebelum dilakukan mutasi

\begin{tabular}{|l|l|l|l|l|l|l|}
\hline 10 & 76 & 23 & 47 & 22 & 9 \\
& & & & & & \\
\hline
\end{tabular}

Setelah dilakukan mutasi

\begin{tabular}{|l|l|l|l|l|l|}
\hline 13 & 76 & 27 & 47 & 22 & 9 \\
\hline & & & & & \\
\hline
\end{tabular}

Gambar 3. Ilustrasi LLH Mutasi

\section{2.2 LLH Local Search}

Konsep dari local search adalah mencari satu kandidat jadwal terbaik saat LLH ini digunakan sehingga tahapan ini akan mencoba semua kandidat pada satu kelas dan menghitung jumlah penalti yang dihasilkan. Setelah itu, akan dicari satu kandidat dengan jumlah penalti terkecil. LLH ini mampu menurunkan jumlah penalti dengan baik, namun cukup menghabiskan waktu karena harus mengecek semua kemungkinan jadwal yang ada. Untuk mengatasi hal tersebut, dilakukan pembatasan. LLH ini akan digunakan jika kandidat dari waktu dikali kandidat ruangan tidak lebih dari 500. 


\section{2.3 Algoritma LAHC}

Kerangka algoritma LAHC yang digunakan mengikuti dari algoritma aslinya. Perubahan dilakukan pada bagian perubahan solusi dengan memasukan LLH mutasi dan local search. Pemilihan kedua LLH dilakukan secara acak. Gambar 4 menunjukan bagaimana alur algoritma LAHC bekerja.

Pada algoritma LAHC, terdapat satu parameter, yaitu panjang list yang digunakan oleh algoritma LAHC sebagai penentu apakah solusi akan digunakan atau tidak. Berdasarkan penelitian yang dilakukan oleh Burke [8], semakin panjang list, solusi yang ditemukan semakin baik. Namun, hal tersebut membutuhkan waktu yang lebih lama. Jika panjang list semakin pendek, penurunan solusi akan lebih cepat daripada list yang panjang. Namun, itu akan rentan terjebak dalam local optima. Penelitian lain yang dilakukan oleh Fonseca [9] yang juga berkaitan dengan penjadwalan pada bidang pendidikan, menemukan nilai parameter panjang list terbaik sebesar 500. Angka ini menghasilkan performa yang baik untuk dataset kecil dan dataset besar. Dengan demikian, penelitian ini akan menggunakan nilai 500 sebagai parameter panjang list pada algoritma LAHC.

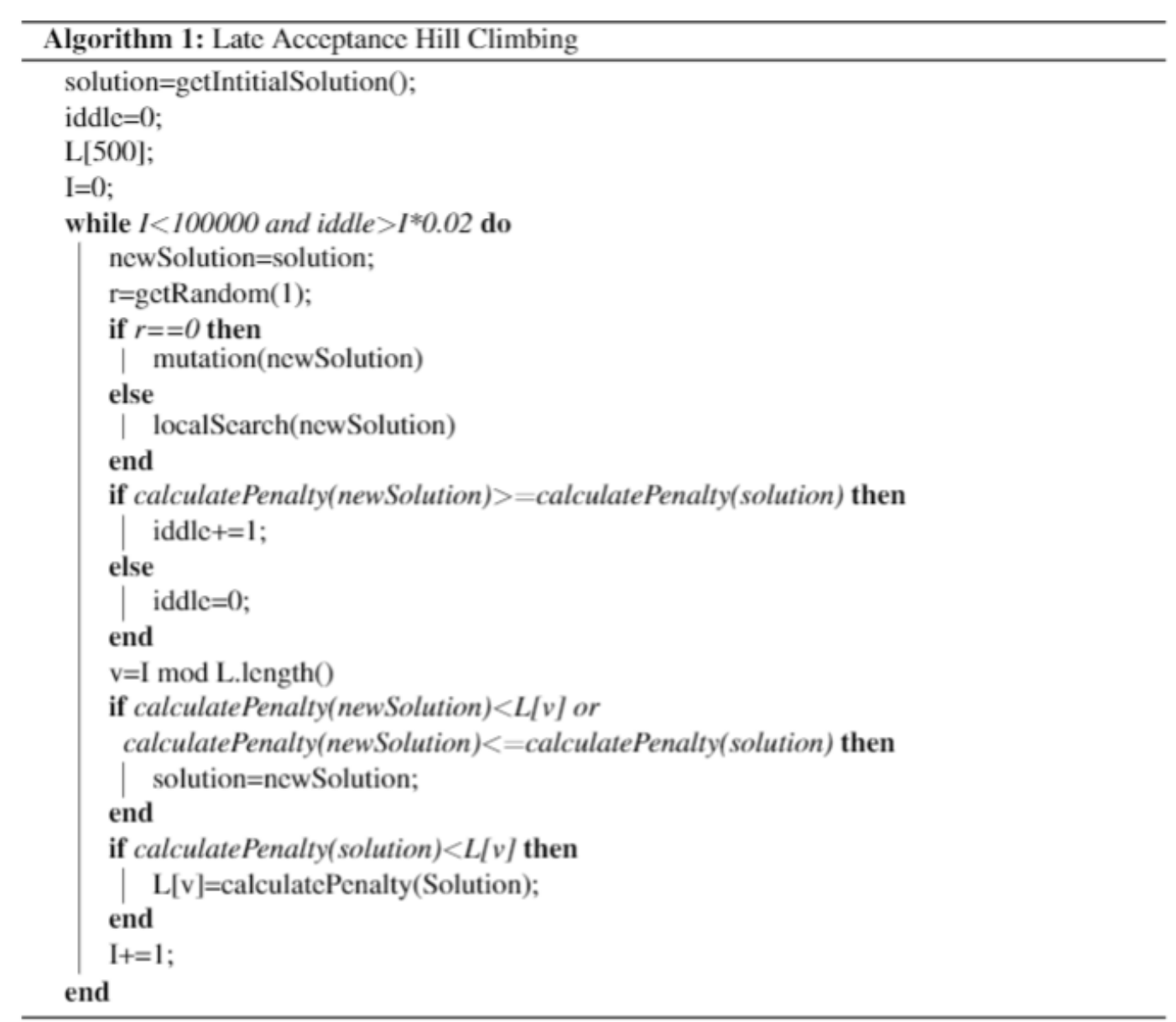

Gambar 4. Algoritma LAHC 


\section{3 Implementasi Algoritma}

Pada bagian ini algoritma yang telah dihasilkan, diimplementasikan dalam bahasa pemrograman java melalui program intelij. 10 dataset tersebut akan dijalankan sebanyak 10 kali disetiap datasetnya dengan jumlah iterasi 100.000 dan waktu maksimal disetiap dataset dalam satu kali iterasi adalah 30 menit.

\section{4 Analisis Hasil}

Dari hasil implementasi pada tahapan sebelumnya dilakukan hasil analisis terhadap persentase optimasi yang berhasil dilakukan dengan membandingkan dari nilai penalti solusi sebelum di optimasi dan sesudah di optimasi. Selain itu persebaran hasil dari 10 kali percobaan akan dilihat dalam grafik box plot untuk melihat seberapa konsisten algoritma ini dalam mengoptimasi solusi.

\section{HASIL DAN PEMBAHASAN}

Setelah dilakukan percobaan terhadap 10 dataset early ITC 2019 pada algoritma LAHC menggunakan pendekatan hiper heuristik dengan 10 kali percobaan pada setiap dataset, menghasilkan hasil berupa rata-rata nilai penalti, nilai penalti terbesar dan nilai penalti terkecil seperti pada tabel 2.

Tabel 2. Hasil Uji Coba Dataset Early ITC 2019

\begin{tabular}{|c|c|c|c|}
\hline Dataset & Rata-Rata Penalti & Penalti Terkecil & Penalti Terbesar \\
\hline agh-fis-spr17 & 9304,167 & 8851 & 9768 \\
\hline agh-ggis-spr17 & 154064,7 & 147981 & 160293 \\
\hline bet-fal17 & 358455,4 & 355526 & 361711 \\
\hline iku-fal17 & 96417,67 & 94673 & 98282 \\
\hline mary-spr17 & 27691,25 & 26775 & 28551 \\
\hline muni-fi-spr16 & 10420,92 & 10229 & 10551 \\
\hline muni-fsps-spr17 & 19308,25 & 17561 & 21464 \\
\hline muni-pdf-spr16c & 415951,4 & 399794 & 443540 \\
\hline pu-llr-spr17 & 65576,83 & 59931 & 72954 \\
\hline tg-fal17 & 12612,08 & 11689 & 13412 \\
\hline
\end{tabular}

Dari hasil percobaan algoritma LAHC dengan pendekatan hiper heuristik mampu mengurangi penalti dengan rata-rata sebesar $52 \%$ dari nilai penalti pada solusi awal. Pada dataset Muni-fsps-spr17 didapatkan pengurangan penalti terbesar yaitu dengan mengurangi penalti sebesar 93\% dari solusi awal. Sedangkan pengurangan penalti terkecil ada pada dataset Bet-fal17 dengan pengurangan penalti sebesar 13\%. Hal ini terjadi karena dataset Bet-fal17, solusi teroptimal yang pernah ditemukan oleh finalis pada kompetisi ITC 2019 yaitu 27\% lebih kecil dari solusi awal atau berbeda $14 \%$ dari solusi akhir pada penelitian ini. Perbandingan pengurangan penalti pada solusi awal dan solusi akhir dapat dilihat pada tabel 3 dan gambar 5 .

Algoritma LAHC dengan pendekatan hiper heuristik melakukan penurunan penalti dengan cepat pada awal iterasi. Setelah itu algoritma ini mampu mengurangi penalti secara perlahan sampai iterasi berakhir. Gambar 6 mengilustrasikan penurunan penalti dari iterasi ke 0 hingga iterasi ke 100.000. Dari sini dapat dilihat bahwa algoritma LAHC mampu bekerja dengan baik dengan tidak terjadi local optima selama iterasi berlangsung dibuktikan dengan mampu mengurangi nilai penalti sampai akhir iterasi. 
Tabel 3. Perbandingan Solusi Awal dan Solusi Akhir B

\begin{tabular}{|c|c|c|c|}
\hline Dataset & Solusi Awal & Solusi Akhir & $\begin{array}{c}\text { Persentase } \\
\text { Pengurangan }\end{array}$ \\
\hline agh-fis-spr17 & 39088 & 8851 & $77 \%$ \\
\hline agh-ggis-spr17 & 194901 & 147981 & $24 \%$ \\
\hline bet-fal17 & 410985 & 355526 & $13 \%$ \\
\hline iku-fal17 & 161686 & 94673 & $41 \%$ \\
\hline mary-spr17 & 75290 & 26775 & $64 \%$ \\
\hline muni-fi-spr16 & 25414 & 10229 & $60 \%$ \\
\hline muni-fsps-spr17 & 242614 & 17561 & $93 \%$ \\
\hline muni-pdf-spr16c & 601148 & 399794 & $33 \%$ \\
\hline pu-llr-spr17 & 136001 & 59931 & $56 \%$ \\
\hline tg-fal17 & 25217 & 11689 & $54 \%$ \\
\hline
\end{tabular}

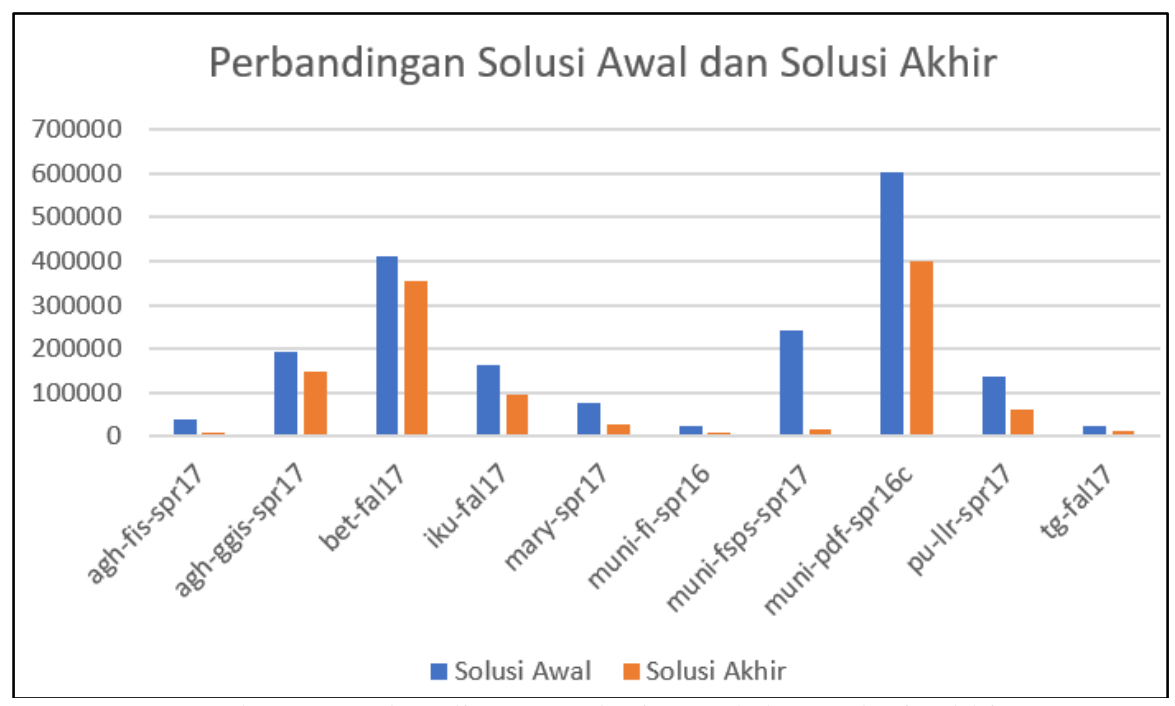

Gambar 5. Perbandingan Solusi Awal dan Solusi Akhir

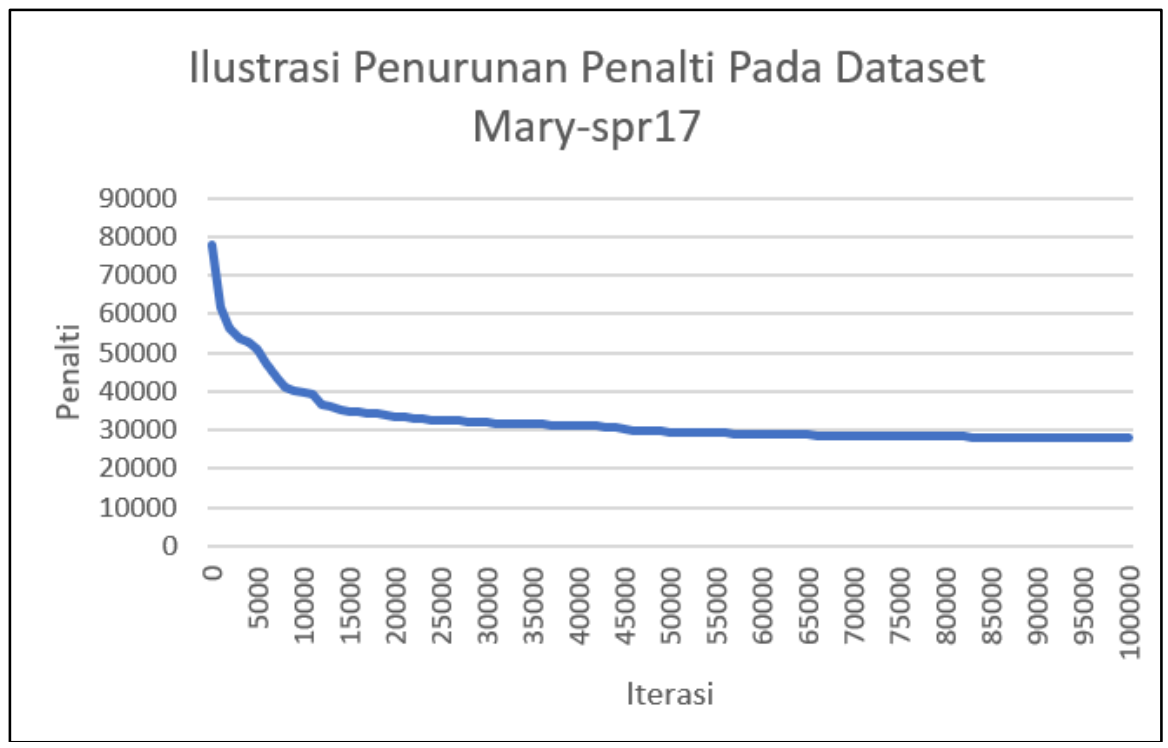

Gambar 6. Ilustrasi Penurunan Penalti pada Dataset Mary-spr17 
Pada persebaran hasil solusi dari 10 kali percobaan, didapatkan algoritma LAHC dengan pendekatan hiper heuristik menghasilkan hasil solusi yang cukup konsistent. Hal ini dapat dilihat pada grafik box-plot pada gambar 7 dan 8 dimana terlihat ukuran candle yang cukup kecil menandakan persebaran solusi yang dihasilkan rapat atau tidak ada perbedaan signifikan antara solusi yang dihasilkan.

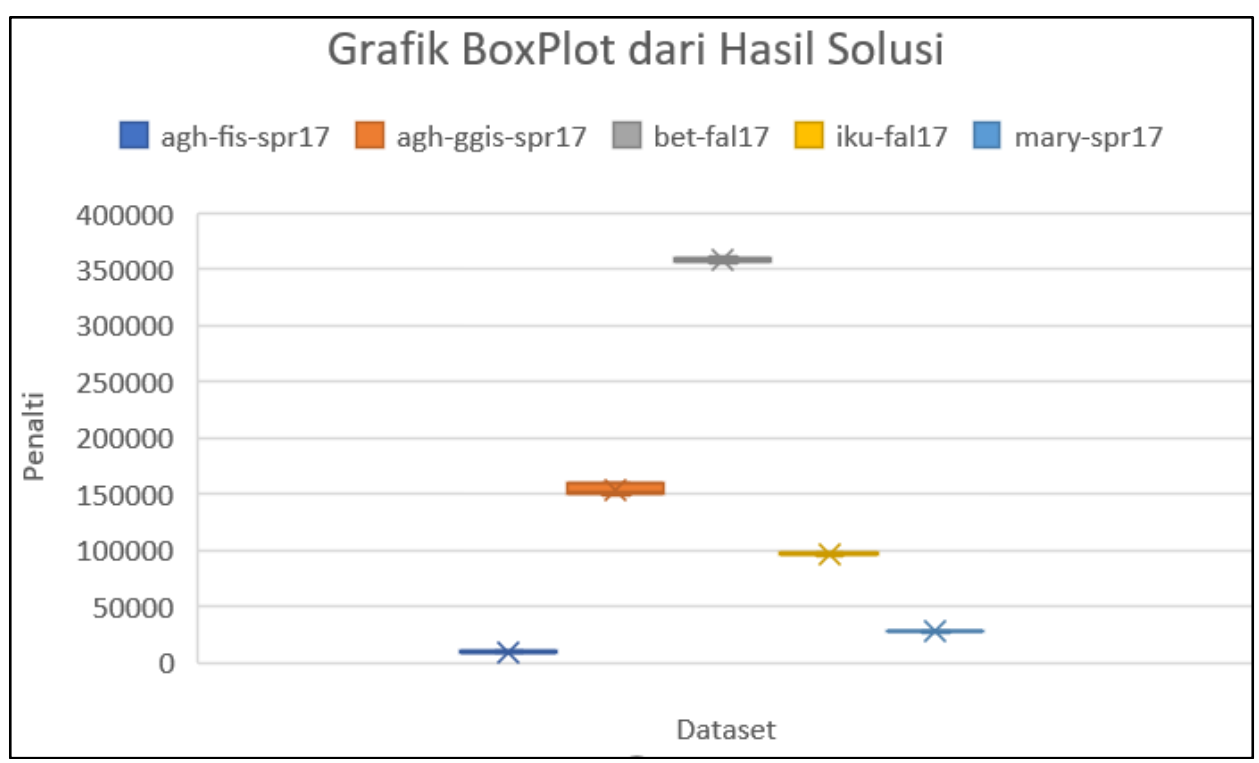

Gambar 7. Grafik Box Plot dari Solusi Akhir

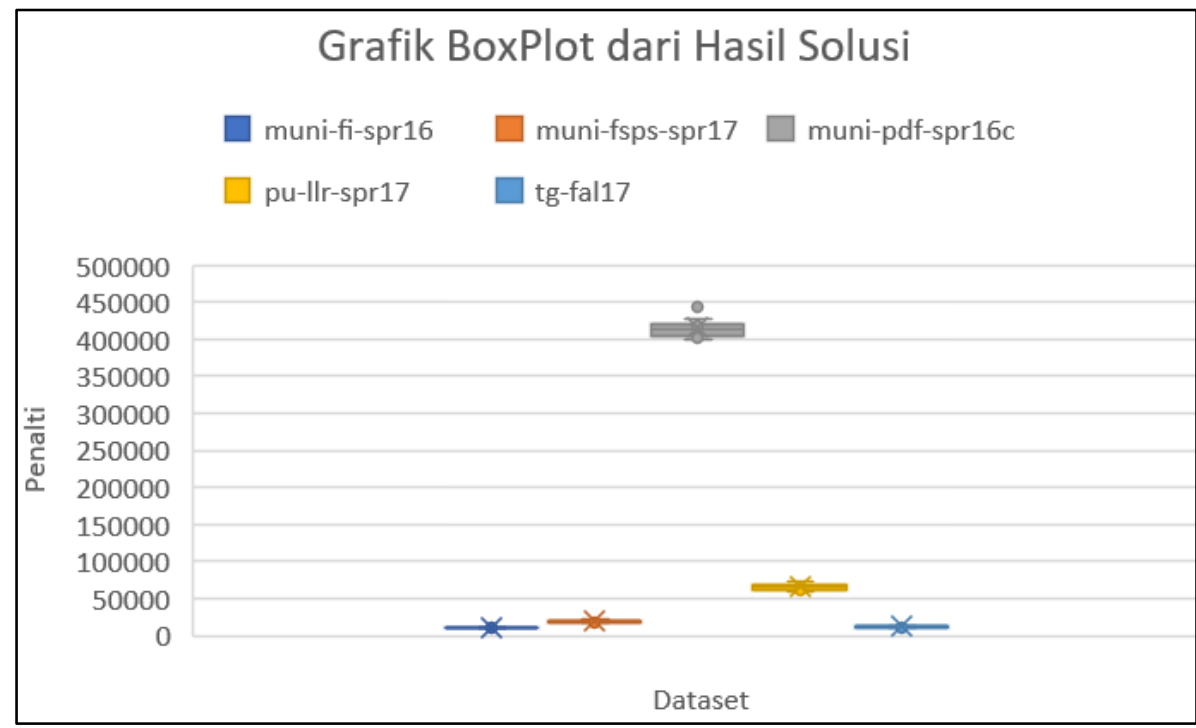

Gambar 8. Grafik Box Plot dari Solusi Akhir

\section{KESIMPULAN}

Berdasarkan hasil penelitian dan pembahasan pada bab sebelumnya, penelitian ini menghasilkan metode baru dengan menghasilkan algoritma LAHC menggunakan pendekatan hiper heuristik dengan menggunakan LLH mutasi dan local search. Algoritma ini mampu mengurangi penalti dari solusi awal dengan rata-rata sebesar $52 \%$ pada 10 dataset early ITC 
2019. Selain itu solusi yang dihasilkan cukup konsisten dibuktikan dengan ukuran candle yang kecil saat dipetakan pada grafik box-plot.

\section{SARAN}

Dalam penelitian ini belum melakukan percobaan terhadap kombinasi LLH lain. Pada penelitian selanjutnya dapat menambahkan atau mengganti LLH yang telah digunakan dengan LLH lainnya seperti swap dan crossover. Dengan mencoba berbagai jenis LLH diharapkan mampu menghasilkan solusi yang lebih baik.

\section{DAFTAR PUSTAKA}

[1] V. I. Skoullis, . I. X. Tassopoulos dan G. N. Beligiannis. 2017, "Solving The High School Timetabling Problem Using A Hybrid Cat Swarm Optimization Based Algorithm," Applied Soft Computing, Vol. 52, pp. 277-289.

[2] T. Song, S. Liu, X. Tang, X. Peng dan M. Chen. 2018, “ An Iterated Local Search Algorithm for The University Course Timetabling Problem," Applied Soft Computing, vol. 68, pp. 597-608

[3] L. Saviniec dan A. A. Constantino. 2017, "Effective Local Search Algorithms for High School Timetabling Problems,” Applied Soft Computing, Vol. 60, pp. 363-373.

[4] M. Alzaqebah dan S. Abdullah. 2015, "Hybrid Bee Colony Optimization for Examination Timetabling Problems," Computers \& Operations Research, Vol. 54, pp. 142-154.

[5] T. M“uller, H. Rudov'a dan Z. M"ullerov'a., 2018, "University Course Timetabling and International Timetabling Competition 2019," Proceedings of The 12th International Conference on The Practice and Theory of Automated Timetabling (PATAT-2018), pp. 531.

[6] E. Burke,, . G. Kendall, . J. Newall dan E. Har, 2003, "Hyper-Heuristics: An Emerging Direction In Modern Search Technology, ” Dalam Handbook of Metaheuristics, Springer, Boston, MA, pp. 457-474.

[7] I. G. A. Premananda. 2021, "Penjadwalan Mata Kuliah Otomatis Menggunakan Algoritma Whale Optimization dan Late Acceptence Hill Climbing," Institut Teknologi Sepuluh Nopember, pp. 1-122,

[8] E. K. Burke dan Y. Bykov. 2017, “The Late Acceptance Hill-Climbing Heuristic," European Journal of Operational Research, Vol. 258, No. 1, pp. 70-78.

[9] G. H. G. Fonseca, H. G. Santos dan E. G. Carrano. 2016, "Late Acceptance HillClimbing for High School Timetabling," Journal of Scheduling, p. 453-465, 